\title{
Post-traumatic stress in the wake of the COVID-19 pandemic:
}

\section{a scoping review [version 1; peer review: 1 approved, 1 approved with reservations]}

\begin{abstract}
Ravi Philip Rajkumar (iD)
Department of Psychiatry, Jawaharlal Institute of Postgraduate Medical Education and Research (JIPMER), Pondicherry, 605006, India
\end{abstract}

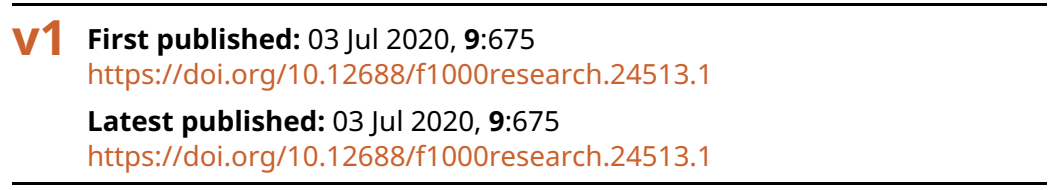

\section{Abstract}

Background: Post-traumatic stress symptoms (PTSS), as well as posttraumatic stress disorder (PTSD) itself, are common sequelae of disasters, including disease outbreaks such as the COVID-19 pandemic. Understanding their frequency and correlates is essential to developing preventive, therapeutic and supportive measures in a time of crisis.

Methods: A scoping review of the literature pertaining to PTSS and PTSD in relation to COVID-19 was carried out with the primary objective of assessing the frequency of PTSS/PTSD and the factors associated with it, and the secondary objective of summarizing expert recommendations in this field. For this purpose, PubMed and Embase literature databases were searched using the terms "COVID-19", "nCoV-2", "post-traumatic stress disorder", "PTSS", "PTSD" and "traumatization" in various combinations. A total of 10 relevant publications were found, which were tabulated and organized into original research on PTSS/PTSD $(n=7)$ and expert opinions or reviews $(n=3)$.

Results: The frequency of PTSS ranged from 7-34\%, depending on study population and methodology. Gender, marital status, physical symptoms, and a prior psychiatric diagnosis were associated with the severity of PTSS. Expert opinions highlighted the prolonged nature of the impact of COVID-19, the need for long-term preventive and treatment strategies, and the need for innovation and collaboration in research and dissemination of information.

Conclusions: The COVID-19 outbreak is likely to leave a large number of persons suffering from PTSD in its wake. The above results may help us to identify those at risk in order to deliver preventive or early therapeutic interventions.

\section{Keywords}

post-traumatic stress disorder, vicarious traumatization, COVID-19

\author{
Open Peer Review \\ Approval Status ? \\ 12 \\ version 1

$\checkmark$
view \\ 03 Jul 2020 \\ 1. Kang Sim, Institute of Mental Health, \\ Singapore, Singapore \\ 2. José María De la Roca-Chiapas (iD), \\ University of Guanajuato, Guanajuato, \\ Mexico \\ Any reports and responses or comments on the \\ article can be found at the end of the article.
}




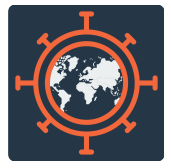

This article is included in the Emerging Diseases

and Outbreaks gateway.

collection.

\section{Corresponding author: Ravi Philip Rajkumar (ravi.psych@gmail.com)}

Author roles: Rajkumar RP: Conceptualization, Data Curation, Formal Analysis, Investigation, Methodology, Project Administration, Validation, Writing - Original Draft Preparation, Writing - Review \& Editing

Competing interests: No competing interests were disclosed.

Grant information: The author(s) declared that no grants were involved in supporting this work.

Copyright: @ 2020 Rajkumar RP. This is an open access article distributed under the terms of the Creative Commons Attribution License, which permits unrestricted use, distribution, and reproduction in any medium, provided the original work is properly cited.

How to cite this article: Rajkumar RP. Post-traumatic stress in the wake of the COVID-19 pandemic: a scoping review [version 1; peer review: 1 approved, 1 approved with reservations] F1000Research 2020, 9:675 https://doi.org/10.12688/f1000research.24513.1

First published: 03 Jul 2020, 9:675 https://doi.org/10.12688/f1000research.24513.1 


\section{Introduction}

Large-scale disasters, such as disease outbreaks, are associated with an increased risk of post-traumatic stress symptoms (PTSS) or post-traumatic stress disorder (PTSS), both in the general population and in high-risk groups such as patients and healthcare workers. Research from earlier outbreaks of a novel coronavirus disease has shown that $25.6 \%$ of survivors of the severe acute respiratory syndrome (SARS) outbreak fulfilled criteria for PTSD at 30 months' follow-up ${ }^{1}$; similarly, both healthcare workers and patients under quarantine reported high levels of PTSS during the Middle East respiratory syndrome (MERS) outbreak ${ }^{2}$. Compared to these earlier outbreaks, which were limited in geographical scope, the global outbreak of novel coronavirus disease (COVID-19) has affected nations all across the globe, with over 3.6 million cases reported to date; therefore, it is logical that this pandemic would have a more profound and widespread psychological impact than its predecessors $^{3,4}$. Some authors have already raised the concern of a "tsunami" of post-traumatic stress disorder sweeping across the globe in the wake of the COVID-19 $\mathrm{crisis}^{5}$, an image which vividly captures the scope of this impact.

The factors involved in psychological traumatization and the development of PTSD during the COVID-19 outbreak are complex and interlinked. To the direct effects of the disease and the fear of infection and death must be added the widespread hypervigilance that is often encouraged by authorities ${ }^{6}$, limitations in the availability of healthcare and other resources ${ }^{5}$, the traumatic effects of measures such as lockdowns, curfews and quarantine $^{7}$, experiences of stigma and discrimination ${ }^{8}$, social isolation and financial hardship ${ }^{9}$ and misinformation about the disease and its origins ${ }^{4}$. Moreover, prolonged contact with those who have been traumatized can itself be traumatic to some, a phenomenon known as vicarious traumatization ${ }^{10}$. Certain groups of people have been identified as being more vulnerable to traumatization during the COVID-19 outbreak, including healthcare professionals and other front-line workers ${ }^{11}$, children and adolescents ${ }^{12}$, the elderly ${ }^{13}$, and those with preexisting psychiatric disorders ${ }^{14}$. More than one of these risk factors or mechanisms may be operative in a given individual.

Thus, the following review was carried out to obtain a preliminary estimate of (a) the frequency of PTSD or PTSS in various populations exposed to the COVID-19 pandemic, and (b) the factors identified as having an association with PTSS and PTSD in published reports. As a secondary objective, a review of expert opinions and commentaries published in this area was also undertaken.

\section{Methods}

The current paper is a scoping review of literature related to PTSD/PTSS during the COVID-19 outbreak. The review protocol for the same is described below, and it was carried out in accordance with the PRISMA-Scoping Review extension guidelines $^{15}$. It has not been formally registered, and further details are available on request from the author.

\section{Search methodology}

All articles which provided either an estimate of the frequency of PTSS or PTSD in relation to the COVID-19 pandemic, the factors associated with such symptomatology, or expert opinions regarding research or patient care in this area, published in the English language between January 1, 2020 and May 15, 2020, were considered for inclusion in the study. The most recent search was conducted on May 17, 2020. Articles were retrieved through a search of the PubMed and Embase databases using the terms "COVID-19", "nCoV-2", "post-traumatic stress disorder", "PTSS", "PTSD" and "traumatization" in various combinations. For example, for the PubMed database, the search strategy was as follows:

1. "COVID-19" (Medical Subheading, Title, Abstract, Text)

2. "Severe Acute Respiratory Syndrome Coronavirus 2" (Supplementary concept)

3. "Post-traumatic Stress Disorder" (Medical Subheading, Title, Abstract, Text)

4. "Post-traumatic Stress" OR "PTSS" OR "PTSD" OR "traumatization" (Title, Abstract, Text)

5. $1 \mathrm{AND}(3 \mathrm{OR} 4)$

6. 2 AND (3 OR 4)

\section{Selection of sources of evidence}

A total of 36 citations were retrieved from PubMed and 38 from EMBASE. After discarding duplicate citations, a total of 36 citations were screened according to the eligibility criteria mentioned above. 12 articles were excluded at this stage as they dealt with topics unrelated to PTSD / PTSS, four were excluded because they were general commentaries on PTSD (without observational data or recommendations) published in Chinese, French or German, and ten were excluded because they were general commentaries on public or mental health that did not specifically discuss PTSD. A total of ten papers - seven observational studies and three expert commentaries, were selected for charting and data synthesis. The details of this process are summarized in Figure 1.

\section{Data synthesis and analysis}

Data was charted in two standardized forms by the author. The first form, which covered the seven observational studies, summarized the data under the following headings: (a) study location; (b) study population (for example: general public, youth, or healthcare workers); (c) psychometric instrument used to measure PTSS and cut-off value used by the authors; (d) reported frequency of PTSS / PTSD expressed as a percentage; (e) subgroup analysis, only if explicitly described by the original researchers (for example: healthcare workers versus the general public); and (f) variables that were significantly associated with an elevated or reduced risk of PTSS / PTSD, as assessed by the author after reviewing all published data (tables and text) provided by the original researchers. Owing to the small number 


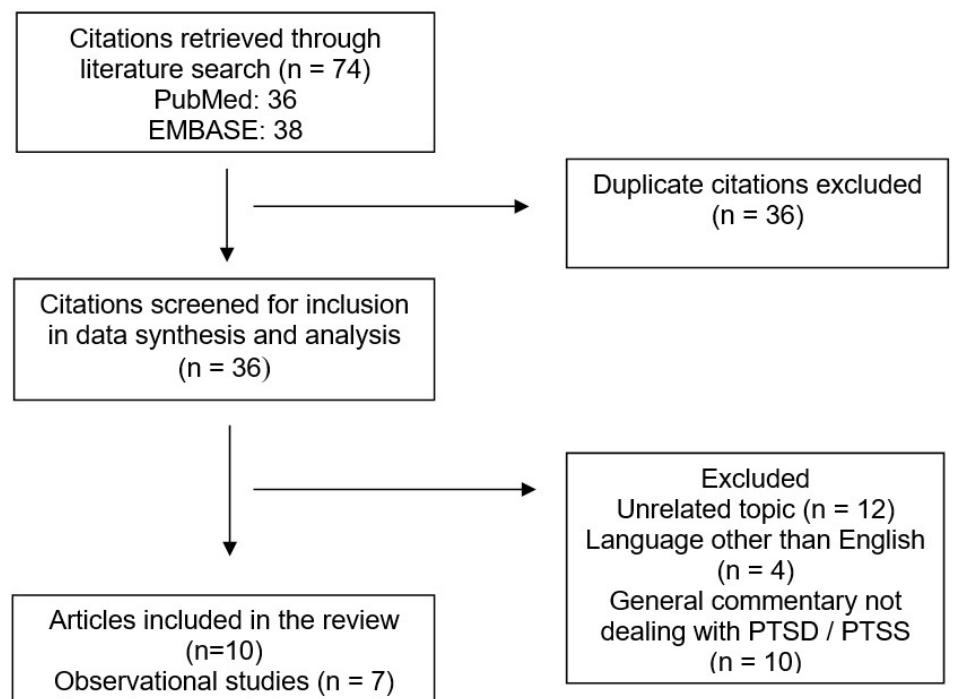

Figure 1. PRISMA-ScR flow diagram for the scoping review.

of studies and the significant heterogeneity in study populations, methodology and outcome measures, a formal statistical summation, such as a pooled prevalence or confidence interval, was not computed. Instead, results were tabulated and presented below in two sections, the first providing estimates of frequency and the second providing details of statistically significant correlates.

The second form, which covered the three expert reviews and recommendations, summarized the data under the following headings: (a) recommendations for prevention of PTSS / PTSD; (b) recommendations for treatment of those identified as having such symptoms; (c) recommendations for policy; and (d) recommendations for future research. As this data was qualitative, no formal statistical analysis was carried out.

\section{Results}

Details of the citations assessed, excluded and selected for inclusion in this review are summarized in the PRISMA flow diagram (Figure 1). Of a total of 36 citations screened for inclusion, 26 were excluded for the following reasons: unrelated topic $(n=12)$, language other than English $(n=4)$, and general review / commentary not specifically addressing PTSD / PTSS $(\mathrm{n}=10)$. A total of ten papers - seven original research studies and three expert commentaries - were selected for the final review, and these are discussed below.

\section{Post-traumatic stress symptoms in individuals during the COVID-19 pandemic}

Five studies reported frequencies and percentages of post-traumatic stress symptoms ${ }^{16-20}$. The results of these studies are summarized in Table 1. All these studies used screening instruments administered remotely through computers or smartphones, with a pre-defined cut-off to estimate the presence of significant
PTSS; in none of them was a formal diagnosis of PTSD confirmed using standard criteria. The most frequently used instrument was the Impact of Event Scale - Revised (IES-R), with a cut-off of 24 used in two papers ${ }^{16,17}$ and 18 in one paper ${ }^{18}$. Estimates of PTSS ranged from 7-34\%, with a pooled frequency of $307 / 2633(11.66 \%)$ across all studies. The use of a lower cut-off value for the IES-R was associated with the highest reported rates of PTSS across these studies.

\section{Other studies of post-traumatic stress during the COVID-19 pandemic}

A longitudinal study of individuals from 190 Chinese cities measured various psychological outcomes, including PTSS, in the general public at two time points: the first during the initial COVID-19 outbreak ( $\mathrm{n}=1210$ ), and the second, four weeks later, during the peak of the epidemic in China $(n=861)^{21}$. The mean IES-R score in this sample decreased significantly over a period of four weeks, from 32.98 to 30.76 ( $p<.01$ ); however, even the follow-up score remained above the pre-defined threshold (24) for significant PTSS, indicating that these symptoms persisted at follow-up, albeit at somewhat lower levels.

A study of vicarious traumatization in a Chinese population, involving 214 members of the general public and 526 nurses and using 38-item questionnaire, found higher levels of vicarious traumatization in the general public $(\mathrm{p}<.001)$ and non-front line nurses $(\mathrm{p}<.001)$ compared to nurses involved in the front-line care of COVID-19 patients $^{22}$; however, PTSS were not directly measured in this study.

Factors associated with PTSS during the COVID-19 pandemic

A number of variables were associated with the presence and severity of PTSS as a result of the COVID-19 pandemic. 
Table 1. Frequency of PTSS in individuals during the COVID-19 pandemic.

\begin{tabular}{|c|c|c|c|}
\hline Authors & Study population and sample size & Study instrument & $\begin{array}{l}\text { Reported frequency } \\
\text { (percentage) }\end{array}$ \\
\hline Liu et al., $2020^{20}$ & $\begin{array}{l}\text { General public, Wuhan, China } \\
(n=285)\end{array}$ & PTSD Checklist for DSM-5 (PCL-5) & $\begin{array}{l}20 / 285 \\
(7.01 \%)\end{array}$ \\
\hline Liang et al., $2020^{19}$ & $\begin{array}{l}\text { Adolescents and young adults (age 14-35), China } \\
(n=584)\end{array}$ & $\begin{array}{l}\text { PTSD Checklist - Civilian Version } \\
\text { (PCL-C) }\end{array}$ & $\begin{array}{l}84 / 584 \\
(14.38 \%)\end{array}$ \\
\hline Tan et al., $2020^{16}$ & $\begin{array}{l}\text { Adults returning to work, China } \\
(n=673)\end{array}$ & $\begin{array}{l}\text { Impact of Event Scale - Revised } \\
\text { (IES-R) }\end{array}$ & $\begin{array}{l}73 / 673 \\
(10.84 \%)\end{array}$ \\
\hline Chew et al., $2020^{17}$ & $\begin{array}{l}\text { Healthcare workers, Singapore and India } \\
(n=906)\end{array}$ & $\begin{array}{l}\text { Impact of Event Scale - Revised } \\
\text { (IES-R) }\end{array}$ & $\begin{array}{l}67 / 906 \\
(7.40 \%)\end{array}$ \\
\hline Hao et al., $2020^{18}$ & $\begin{array}{l}\text { Patients with anxiety disorders and depression }(n=76) \\
\text { and healthy controls } \\
(n=109)\end{array}$ & $\begin{array}{l}\text { Impact of Event Scale - Revised } \\
\text { (IES-R) }\end{array}$ & $\begin{array}{l}63 / 185 \\
(34.05 \%)^{+}\end{array}$ \\
\hline
\end{tabular}

Female gender was associated with the severity of PTSS in two studies $^{19,20}$, but one paper found an association with male gender; however, this study was specifically focused on people returning to work during the pandemic ${ }^{16}$. Other socio-demographic predictors of significance included younger age (12-21 years), a higher number of persons per household ${ }^{21}$, widowed, separated or divorced marital status ${ }^{16,19}$, lower educational qualifications, and employment in the business sector ${ }^{18}$. Physical symptoms resembling those of COVID-19, such as fever, sore throat, cough, myalgia and fatigue, were associated with PTSS in two studies $^{17,20}$, one of which involved health workers exclusively; other physical variables associated with PTSS were self-rated poor health ${ }^{16}$ and poor sleep quality ${ }^{20}$. Pre-existing anxiety disorder or depressive disorder were associated with a higher frequency of PTSS than that observed in controls without a psychiatric diagnosis $(43.4 \% \text { vs } 27.5 \% \text {; } p=.025)^{17}$. Finally, individual and institutional adherence to hygienic precautions, such as hand hygiene and social distancing, were associated with reduced severity of $\mathrm{PTSS}^{16}$.

\section{Expert opinions and recommendations}

In a paper examining the methodological and practical gaps related to the assessment of PTSS during the COVID19 pandemic, Horesh and Brown provided several relevant recommendations ${ }^{6}$. From a conceptual viewpoint, they highlighted the fact that trauma and PTSD were not yet part of the public discourse on the impact of COVID-19, as opposed to general terms such as "anxiety" and "fear". From a methodological viewpoint, they discussed the potential usefulness of machine learning methods and ecological momentary assessments in studying PTSD and its correlates in large samples, as well as the need to investigate biological markers (such as markers of inflammation) that could be associated with an increased risk of PTSD. From a preventive point of view, the usefulness of psychological first aid and the need to focus on high-risk populations, including healthcare workers, was emphasized. Finally, in terms of public outreach, the need to disseminate high quality information about trauma and its manifestations, and to work more closely with non-mental health services, were both discussed. These recommendations are undoubtedly of use to anyone involved in developing a robust response to PTSS/PTSD in the context of COVID-19. From a more immediately practical perspective, Dutheil et al. estimated that around $30-50 \%$ of the population affected by the COVID-19 pandemic might exhibit PTSS to some degree, and underlined the association between PTSD and suicide. They concluded that both these facets would need to be addressed through public health policy ${ }^{5}$. Finally, a paper comparing the impact of COVID-19 with the September 11, 2001 terrorist attack noted that the effects of COVID-19 in terms of psychological trauma were likely to be far more protracted, and that long-term follow-up care to address chronic PTSD would consequently be required ${ }^{23}$.

\section{Conclusions}

Though the existing literature is confined to cross-sectional studies using screening tools, it is clear that significant PTSS affect a sizeable minority of individuals facing the consequences of the COVID-19 pandemic. Some of the variables associated with the severity of PTSS, such as female gender and separated/divorced marital status, have been reported in earlier studies of PTSD following disasters ${ }^{24,25}$; however, factors such as the presence of physical symptoms or poor perceived physical health are more likely to be specific to disease outbreaks. As there is an overlap between the factors identified in this review and those related to depressive or anxiety symptoms during the COVID-1926, they may represent general predisposing factors for psychological morbidity, rather than having a specific association with PTSD. Evidence from the only longitudinal study available to date suggests that PTSS are relatively stable over a period of four weeks. Literature from the SARS outbreak suggests that symptoms of 
PTSS persist in over half of those initially affected after over two years ${ }^{1}$; thus, further longitudinal studies are needed to examine the persistence of PTSS/PTSD in the aftermath of the COVID-19 pandemic and the factors associated with it.

This review is subject to certain important limitations. First, because of the limited literature in this field, this was a scoping review rather than a systematic review or meta-analysis, and its statistical rigour is accordingly limited. Second, all reviewed studies bar one were cross-sectional studies, allowing few conclusions to be drawn about the long-term course of PTSS in these individuals. Third, all studies relied on screening instruments, and hence were more likely to capture initial and acute responses to stress rather than PTSD itself, which may develop after several weeks or months. Fourth, most published studies were from a single geographical area, and their findings may not be entirely applicable to other countries and cultures.
Despite these important caveats, there is enough evidence to suggest that PTSS is and will continue to be a significant problem as the COVID-19 pandemic continues to run its course. It is hoped that the findings summarized and reviewed above may be of use to researchers in this field, as well as to those involved in the identification, prevention, and management of post-traumatic stress related to COVID-19 at the clinic and community level.

\section{Data availability}

All data underlying the results are available as part of the article and no additional source data are required.

\section{Acknowledgments}

The author wishes to thank all the researchers and publishers who have made literature in this field easily accessible at a time of crisis.
1. Mak IWC, Chu CM, Pan PC, et al:: Long-term psychiatric morbidities among SARS survivors. Gen Hosp Psychiatry. 2009; 31(4): 318-326. PubMed Abstract | Publisher Full Text | Free Full Text

2. Lee SM, Kang WS, Cho AR, et al:: Psychological impact of the $\mathbf{2 0 1 5}$ MERS outbreak on hospital workers and quarantined hemodialysis patients. Compr Psychiatry. 2018; 87: 123-127.

PubMed Abstract | Publisher Full Text | Free Full Text

3. Maunder RG: Was SARS a mental health catastrophe? Gen Hosp Psychiatry. 2009; 31(4): 316-317.

PubMed Abstract | Publisher Full Text | Free Full Text

4. Jakovljevic M, Bjedov S, Jacksic N, et al:: COVID-19 pandemia and public and global mental health from the perspective of global health security. Psychiatr Danub. 2020; 32(1): 6-14.

PubMed Abstract | Publisher Full Text

5. Dutheil F, Mondillon L, Navel V: PTSD as the second tsunami of the SARS-CoV-2 pandemic. Psychol Med. 2020; 1-2.

PubMed Abstract | Publisher Full Text | Free Full Text

6. Horesh D, Brown AD: Traumatic stress in the age of CoviD-19: a call to close critical gaps and adapt to new realities. Psychol Trauma. 2020; 12(4): 331-335.

PubMed Abstract | Publisher Full Text

7. Brooks SK, Webster RK, Smith LE, et al.: The psychological impact of quarantine and how to reduce it: rapid review of the evidence. Lancet. 2020; 395(10227): 912-920.

PubMed Abstract | Publisher Full Text | Free Full Text

8. Chew QH, Wei KC, Vasoo S, et al:: Narrative synthesis of psychological and coping responses towards emerging infectious disease outbreaks in the general population: practical considerations for the COVID-19 pandemic. Singapore Med J. 2020.

PubMed Abstract | Publisher Full Text

9. Pfefferbaum B, North CS: Mental health and the COVID-19 pandemic. N Engl $J$ Med. 2020; 1: 1-2.

PubMed Abstract | Publisher Full Text

10. Jenkins SR, Baird S: Secondary traumatic stress and vicarious trauma: a validational study. J Trauma Stress. 2002; 15(5): 423-32. PubMed Abstract | Publisher Full Text

11. Williamson V, Murphy D, Greenberg N: COVID-19 and experiences of moral injury in front-line key workers. Occup Med (Lond). 2020; kqaa052. PubMed Abstract | Publisher Full Text | Free Full Text

12. Green P: Risks to children and young people during COVID-19 pandemic. BMJ. 2020; 369: m1669.

PubMed Abstract | Publisher Full Text

13. Yang Y, Li W, Zhang Q, et al.: Mental health services for older adults in China during the COVID-19 outbreak. Lancet Psychiatry. 2020; 7(4): e19. PubMed Abstract | Publisher Full Text | Free Full Text

14. Yao H, Chen JH, Xu YF: Patients with mental health disorders in the COVID-19 epidemic. Lancet Psychiatry. 2020; 7(4): e21. PubMed Abstract | Publisher Full Text | Free Full Text

15. Tricco AC, Lillie E, Zarin W, et al.: PRISMA extension for scoping reviews
(PRISMA-ScR): checklist and explanation. Ann Intern Med. 2018; 169(7): 467-473.

PubMed Abstract | Publisher Full Text

16. Tan $\mathrm{W}$, Hao F, Mclntyre RS, et al:: Is returning to work during the COVID-19 pandemic stressful? A study on immediate mental health status and psychoneuroimmunity prevention measures of Chinese workforce. Brain Behav Immun. 2020; S0889-1591(20)30603-6.

PubMed Abstract | Publisher Full Text | Free Full Text

17. Chew NWS, Lee GKH, Tan BYQ, et al:: A multinational, multicentre study on the psychological outcomes and associated physical symptoms amongst healthcare workers during COVID-19 outbreak. Brain Behav Immun. 2020; S0889-1591(20)30523-7.

PubMed Abstract | Publisher Full Text | Free Full Text

18. Hao F, Tan W, Jiang L, et al.: Do psychiatric patients experience more psychiatric symptoms during COVID-19 pandemic and lockdown? A casecontrol study with service and research implications for immunopsychiatry. Brain Behav Immun. 2020.

PubMed Abstract | Publisher Full Text | Free Full Text

19. Liang $\mathrm{L}$, Ren $\mathrm{H}, \mathrm{Cao}$ R, et al.: The effect of COVID-19 on youth mental health. Psychiatr Q. 2020; 1-12.

PubMed Abstract | Publisher Full Text | Free Full Text

20. Liu N, Zhang F, Wei C, et al.: Prevalence and predictors of PTSS during COVID-19 in China hardest-hit areas: gender differences matter. Psychiatry Res. 2020; 288: 112921.

PubMed Abstract | Publisher Full Text | Free Full Text

21. Wang C, Pan R, Wan X, et al:: A longitudinal study on the mental health of general population during the COVID-19 epidemic in China. Brain Behav Immun. 2020.

PubMed Abstract | Publisher Full Text | Free Full Text

22. Li Z, Ge J, Yang M, et al.: Vicarious traumatization in the general public, members, and non-members of medical teams aiding in COVID-19 control. Brain Behav Immun. 2020.

PubMed Abstract | Publisher Full Text | Free Full Text

23. DePierro J, Lowe S, Katz C: Lessons learned from 9/11: mental health perspectives on the COVID-19 pandemic. Psychiatry Res. 2020; 288: 113024 PubMed Abstract | Publisher Full Text | Free Full Text

24. Kun $\mathrm{P}$, Tong $\mathrm{X}$, Liu $\mathrm{Y}$, et al:: What are the determinants of post-traumatic stress disorder: age, gender, ethnicity or other? Evidence from 2008 Wenchuan earthquake. Public Health. 2013; 127(7): 644-52. PubMed Abstract | Publisher Full Text

25. Lowe SR, Bonumwezi JL, Valdespino-Hayden Z, et al.: Posttraumatic stress and depression in the aftermath of environmental disasters: a review of quantitative studies published in 2018. Curr Environ Health Rep. 2019; 6(4): 344-360. PubMed Abstract | Publisher Full Text

26. Wang $\mathrm{C}$, Pan R, Wan X, et al.: Immediate psychological responses and associated factors during the initial stage of the 2019 coronavirus disease (COVID-19) epidemic among the general population in China. Int J Environ Res Public Health. 2020; 17(5): 1729

PubMed Abstract | Publisher Full Text | Free Full Text 


\section{Open Peer Review}

\section{Current Peer Review Status:}

\section{Version 1}

Reviewer Report 01 April 2021

https://doi.org/10.5256/f1000research.27040.r71936

(C) 2021 De la Roca-Chiapas J. This is an open access peer review report distributed under the terms of the Creative Commons Attribution License, which permits unrestricted use, distribution, and reproduction in any medium, provided the original work is properly cited.

\section{? José María De la Roca-Chiapas}

Department of Psychology, University of Guanajuato, Guanajuato, Mexico

Post-traumatic stress in the wake of the COVID-19 pandemic: a scoping review It is an interesting article that presents useful information on the subject of COVID-19. It is well presented, only it has a methodological error, which limits the results and its scope which I detail below:

- The time of selection of the articles is very short, I would ask if it is your interest in indexing it, that the search will increase until September or October 2020, since a lot of information has been generated in this regard and not including it would be wasting the article.

You could also modify the title of the article and remove "in the wake".

You could also compare how it has occurred in different parts of the world since it is a global problem.

\section{References}

1. González Ramírez LP, Martínez Arriaga RJ, Hernández-Gonzalez MA, De la Roca-Chiapas JM: Psychological Distress and Signs of Post-Traumatic Stress in Response to the COVID-19 Health Emergency in a Mexican Sample.Psychol Res Behav Manag. 2020; 13: 589-597 PubMed Abstract I Publisher Full Text

Is the topic of the review discussed comprehensively in the context of the current literature?

Partly

Are all factual statements correct and adequately supported by citations? Yes

Is the review written in accessible language? 
Yes

Are the conclusions drawn appropriate in the context of the current research literature? Partly

Competing Interests: No competing interests were disclosed.

Reviewer Expertise: Stress, Psychology

I confirm that I have read this submission and believe that I have an appropriate level of expertise to confirm that it is of an acceptable scientific standard, however I have significant reservations, as outlined above.

Reviewer Report 11 March 2021

\section{https://doi.org/10.5256/f1000research.27040.r77520}

(C) $2021 \mathrm{Sim}$ K. This is an open access peer review report distributed under the terms of the Creative Commons Attribution License, which permits unrestricted use, distribution, and reproduction in any medium, provided the original work is properly cited.

\section{Kang Sim}

Department of General Psychiatry, Institute of Mental Health, Singapore, Singapore

The paper reads well, the methods are appropriate and the author should consider the following suggestions to improve the paper:

1. The rationale for choosing a scoping review over a systematic review can be briefly explained.

2. It would be good to state the exclusion criteria under the "Search Methodology" section as well.

Is the topic of the review discussed comprehensively in the context of the current literature?

Yes

Are all factual statements correct and adequately supported by citations?

Yes

Is the review written in accessible language?

Yes

Are the conclusions drawn appropriate in the context of the current research literature? Yes

Competing Interests: No competing interests were disclosed. 
Reviewer Expertise: Adult Psychiatry

I confirm that I have read this submission and believe that I have an appropriate level of expertise to confirm that it is of an acceptable scientific standard.

The benefits of publishing with F1000Research:

- Your article is published within days, with no editorial bias

- You can publish traditional articles, null/negative results, case reports, data notes and more

- The peer review process is transparent and collaborative

- Your article is indexed in PubMed after passing peer review

- Dedicated customer support at every stage

For pre-submission enquiries, contact research@f1000.com 